ISSN 2332-2926

\title{
Synchronous Primary Endometrial and Ovarian Cancers: Pathogenesis, Treatment and Prognosis
}

Androutsopoulos $G^{1 *}$, Decavalas $G^{1}$

Editorial

${ }^{1}$ Department of Obstetrics and Gynecology, University of Patras, Medical School, Rion, Greece.

\section{*Corresponding Author:}

Georgios Androutsopoulos MD,

Lecturer, Department of Obstetrics and Gynecology,

University of Patras, Medical School,

Rion 26504, Greece.

Tel: +306974088092

E-mail: androutsopoulos@upatras.gr

Received: August 02, 2014

Published: August 27, 2014

Citation: Androutsopoulos G, Decavalas G (2014) Synchronous Primary Endometrial and Ovarian Cancers: Pathogenesis, Treatment and Prognosis. Int J Clin Ther Diagn. 2(4e), 1-2. doi: http://dx.doi. org/10.19070/2332-2926-140005e

Copyright: Georgios Androutsopoulos ${ }^{\mathscr{O}}$ 2014. This is an open-access article distributed under the terms of the Creative Commons Attribution License, which permits unrestricted use, distribution and reproduction in any medium, provided the original author and source are credited.

Synchronous primary cancers are relatively uncommon in general population.[1] Only $0.5-1.7 \%$ of women with gynecological malignancies, have synchronous primary cancers of the female genital tract.[2-6] Among them, the most common combination is synchronous primary endometrial and ovarian cancers. $[2,3,5]$

The pathogenesis of synchronous primary endometrial and ovarian cancers, remains unclear[5,7] The theory of the secondary Müllerian system has been proposed to explain the development of multiple primary cancers of the female genital tract.[5-9] According to this theory, epithelia of the female genital tract simultaneously respond to a carcinogenic stimulus. $[7,8]$

Perhaps those patients have a more fragile genome and prior genetic damage may predispose to the development of synchronous primary cancers of the female genital tract.[7,10-14] Thus, embryologic, hormonal or other phenomena may be associated with the development of synchronous primary endometrial and ovarian cancers. $[5-10,12]$

Systematic surgical staging is the treatment of choice, for most patients with synchronous primary endometrial and ovarian cancers[2,3,5,15-21] More specifically, systematic surgical staging in those patients includes: total abdominal hysterectomy with bilateral salpingo-oophorectomy, total omentectomy, appendectomy, pelvic and para-aortic lymphadenectomy, complete resection of all disease, biopsy of any suspected lesion and pelvic washings. $[1,2,5,15-19,21-23]$

It is obvious that systematic surgical staging allows a more clear decision for stage related postoperative adjuvant treatment.
$[1,17,18]$ Appropriate surgical staging facilitates targeted therapy that minimize the morbidity of overtreatment (radiation injury, chemotherapy toxicity), the effects of undertreatment (recurrent disease, increased mortality) and maximize survival.[24]

Pelvic and para-aortic lymphadenectomy has diagnostic, therapeutic and prognostic value.[1,22,23] It defines accurately the extent of disease and determines the prognosis of patients.[1] Undoubtedly, it is necessary for the identification of patients with stage III disease. [22,23] The extension of pelvic and para-aortic lymphadenectomy (more than 14 lymph nodes) is an independent risk factor for postoperative complications.[17,18,25-27] Especially in elderly patients and in patients with relevant comorbidities (obesity, diabetes, coronary artery disease), morbidity must be carefully weighed against any survival advantage.[24,28,29]

The significance of postoperative adjuvant treatment in patients with synchronous primary endometrial and ovarian cancers, remains controversial and needs further investigation.[16,20,30] In most cases, postoperative adjuvant treatment should be individualized according to the risk of relapse of each primary cancer. $[30,31]$ Moreover, the treatment of one primary cancer does not compromise the treatment of the other primary cancer. [32]

Especially in patients with unfavorable histologic types, high grade and/or advanced stage disease, required postoperative adjuvant treatment tailored to both tumors.[3,5,15,17-21,30,32-36] More specifically, postoperative adjuvant treatment in those patients includes: radiotherapy and/or chemotherapy.[1,21,30,36]

Postoperative adjuvant radiotherapy includes: external pelvic radiotherapy and/or brachytherapy. It is the appropriate treatment for high risk primary endometrial cancer.[1,17,18]

Postoperative adjuvant chemotherapy is the appropriate treatment for advanced stage primary endometrial and ovarian cancers. [31] The most active chemotherapeutic agents for those patients, are: taxanes, anthracyclines and platinum compounds. [20,21]

Prognostic factors for synchronous primary endometrial and ovarian cancers are: age, grade of endometrial cancer, stage of ovarian cancer and adjuvant treatment. [35,37,38] Patients with synchronous primary endometrial and ovarian cancers have 5 -year overall survival $85.9 \%$ and 10 year overall survival 80.3\%.[16] However, patients with synchronous primary endometrial and ovarian cancers endometrioid type have a better overall survival compared with patients with non-endometrioid or mixed histologic types. [39] Moreover, patients with synchronous primary endometrial and ovarian cancers have better overall survival compared with patients with single primary ovarian cancer. $[30,32,35,39]$ 
The reason for the better overall survival of patients with synchronous primary endometrial and ovarian cancers, is not intuitively obvious.[16] Perhaps favorable prognosis related with the detection of patients at early stage and low grade disease. $[3,5,11$ $13,15-34,40]$

\section{References}

[1]. Androutsopoulos G, Decavalas G. (2013) Synchronous primary endometrial and ovarian cancers. J Community Med Health Educ 3(7): 120.

[2]. Tong SY, Lee YS, Park JS, Bae SN, Lee JM,et al (2008) Clinical analysis of synchronous primary neoplasms of the female reproductive tract. Eur J Obstet Gynecol Reprod Biol 136(1):78-82.

[3]. Ayhan A, Yalcin OT, Tuncer ZS, Gurgan T, Kucukali T. (1992) Synchronous primary malignancies of the female genital tract. Eur J Obstet Gynecol Reprod Biol 45(1):63-6.

[4]. Matlock D, Salem F, Charles E, Savage E. (1982) Synchronous multiple primary neoplasms of the upper female genital tract. Gynecol Oncol 13(2):271-7.

[5]. Eisner R, Nieberg R, Berek J. (1989) Synchronous primary neoplasms of the female reproductive tract. Gynecol Oncol 33(3):335-9.

[6]. Deligdisch L, Szulman A. (1975) Multiple and multifocal carcinomas in female genital organs and breast. Gynecol Oncol 3(3):181-90.

[7]. Woodruff JD, Solomon D, Sullivant H. (1985) Multifocal disease in the upper genital canal. Obstet Gynecol 65(5):695-8.

[8]. Lauchlan S. (1972) The secondary Mullerian system. Obstet Gynecol Surv 27(3):133-46.

[9]. Sica V, Nola E, Contieri E, Bova R, Masucci M, et al. (1984) Estradiol and progesterone receptors in malignant gastrointestinal tumors. Cancer Res 44(10):4670-4.

[10]. Herrinton L, Voigt L, Weiss N, Beresford S, Wingo P. (2001) Risk factors for synchronous primary endometrial and ovarian cancers. Ann Epidemiol 11(8):529-33.

[11]. Terzakis E, Androutsopoulos G, Grigoriadis C, Zygouris D, Derdelis G, et al. (2010) Synchronous primary endometrial and fallopian tube cancers. Eur J Gynaecol Oncol 31(4):467-8.

[12]. Androutsopoulos G, Adonakis G, Tsamantas A, Liosis S, Antonopoulos A, et al. (2008) Synchronous primary cancers in a woman with scleroderma: a case report. Eur J Gynaecol Oncol 29(5):548-50.

[13]. Decavalas G, Adonakis G, Androutsopoulos G, Gkogkos P, Koumoundourou D, et al. (2006) Synchronous primary endometrial and ovarian cancers: a case report. Eur J Gynaecol Oncol 27(4):434-6.

[14]. Grigoriadis C, Androutsopoulos G, Zygouris D, Arnogiannaki N, Terzakis E. (2012) Synchronous squamous cell carcinoma of the endometrium and endometrioid adenocarcinoma of the ovary. Eur J Gynaecol Oncol 33(6):666-8.

[15]. Androutsopoulos G, Adonakis G, Tsamandas A, Andonopoulos A, Decavalas G. (2011) Systemic Sclerosis and Multiple Cancers of the Female Genital Tract: Prolonged Survival following Current Treatment Strategies. Case Rep Rheumatol 2011:392068.

[16]. Zaino R, Whitney C, Brady MF, DeGeest K, Burger RA, et al. (2001) Simultaneously detected endometrial and ovarian carcinomas--a prospective clinicopathologic study of 74 cases: a gynecologic oncology group study. Gynecol Oncol 83(2):355-62.

[17]. Androutsopoulos G, Decavalas G. (2013) Management of endometrial cancer. International Journal of Translation \& Community Medicine 1(1):101.

[18]. Androutsopoulos G. (2012) Current treatment options in patients with endometrial cancer. J Community Med Health Educ 2(12):e113.

[19]. Signorelli M, Fruscio R, Lissoni A, Pirovano C, Perego P, et al. (2008) Synchronous early-stage endometrial and ovarian cancer. Int J Gynaecol Obstet
102(1):34-8.

[20]. Chiang Y, Chen C, Huang C, Hsieh C, Cheng W. (2008) Synchronous primary cancers of the endometrium and ovary. Int $\mathrm{J}$ Gynecol Cancer 18(1):159-64

[21]. Liu Y, Li J, Jin H, Lu Y, Lu X. (2013) Clinicopathological characteristics of patients with synchronous primary endometrial and ovarian cancers: A review of 43 cases. Oncol Lett 5(1):267-70.

[22]. Prat J. (2014) Staging classification for cancer of the ovary, fallopian tube, and peritoneum. Int J Gynaecol Obstet 124(1):1-5.

[23]. Pecorelli S. (2009) Revised FIGO staging for carcinoma of the vulva, cervix, and endometrium. Int J Gynaecol Obstet 105(2):103-4.

[24]. ACOG. (2005) practice bulletin \#65: management of endometrial cancer. Obstet Gynecol 106(2):413-25.

[25]. Benedetti Panici P, Basile S, Maneschi F, Alberto Lissoni A, Signorelli M, et al. (2008) Systematic pelvic lymphadenectomy vs. no lymphadenectomy in early-stage endometrial carcinoma: randomized clinical trial. J Natl Cancer Inst 100(23):1707-16

[26]. Franchi M, Ghezzi F, Riva C, Miglierina M, Buttarelli M,et al. (2001) Postoperative complications after pelvic lymphadenectomy for the surgical staging of endometrial cancer. J Surg Oncol 78(4):232-7

[27]. May K, Bryant A, Dickinson H, Kehoe S, Morrison J. (2010) Lymphadenectomy for the management of endometrial cancer. Cochrane Database Syst Rev (1):CD007585

[28]. Lachance J, Darus C, Rice L. (2008) Surgical management and postoperative treatment of endometrial carcinoma. Rev Obstet Gynecol 1(3):97-105.

[29]. Lowery W, Gehrig P, Ko E, Secord A, Chino J, et al. (2012) Surgical staging for endometrial cancer in the elderly - is there a role for lymphadenectomy? Gynecol Oncol 126(1):12-5.

[30]. Ma S, Zhang H, Sun Y, Wu L. (2009) Synchronous primary cancers of the endometrium and ovary: review of 43 cases. Chinese-German Journal of Clinical Oncology 8(2):95-9.

[31]. Heitz F, Amant F, Fotopoulou C, Battista MJ, Wimberger P, et al. (2014) Synchronous ovarian and endometrial cancer-an international multicenter case--control study. Int J Gynecol Cancer 24(1):54-60.

[32]. Castro I, Connell P, Waggoner S, Rotmensch J, Mundt A. (2000) Synchronous ovarian and endometrial malignancies. Am J Clin Oncol 23(5):521-5.

[33]. Eifel P, Hendrickson M, Ross J, Ballon S, Martinez A, et al. (1982) Simultaneous presentation of carcinoma involving the ovary and the uterine corpus. Cancer 50(1):163-70.

[34]. Sheu BC, Lin HH, Chen CK, Chao KH, Shun CT, et al. (1995) Synchronous primary carcinomas of the endometrium and ovary. Int J Gynaecol Obstet 51(2):141-6.

[35]. Lim Y, Padma R, Foo L, Chia Y, Yam P, et al. (2011) Survival outcome of women with synchronous cancers of endometrium and ovary: a 10 year retrospective cohort study. J Gynecol Oncol 22(4):239-43.

[36]. Pearl ML, Johnston CM, Frank TS, Roberts JA. (1993) Synchronous dual primary ovarian and endometrial carcinomas. Int J Gynaecol Obstet 43(3):305-12.

[37]. Ayhan A, Guvenal T, Coskun F, Basaran M, Salman MC. (2003) Survival and prognostic factors in patients with synchronous ovarian and endometrial cancers and endometrial cancers metastatic to the ovaries. Eur J Gynaecol Oncol 24(2):171-4.

[38]. Song T, Seong S, Bae D, Kim J, Suh D, et al. (2014) Prognostic factors in women with synchronous endometrial and ovarian cancers. Int J Gynecol Cancer 24(3):520-7.

[39]. Soliman PT, Slomovitz BM, Broaddus RR, Sun CC, Oh JC, et al. (2004) Synchronous primary cancers of the endometrium and ovary: a single institution review of 84 cases. Gynecol Oncol 94(2):456-62.

[40]. van Altena A, Geels Y, Bulten J, Kiemeney L, de Hullu J, et al. (2012) Why do women with double primary carcinoma of the endometrium and ovary have a favorable prognosis? Int J Gynecol Pathol 31(4):344-51. 